\title{
Philippe Willemart, Critique génétique: pratiques et théories
}

\section{Geneviève Henrot Sostero}

\section{(2) OpenEdition \\ 1 Journals}

\section{Édition électronique}

URL : http://journals.openedition.org/studifrancesi/9023

DOI : 10.4000/studifrancesi.9023

ISSN : 2421-5856

Éditeur

Rosenberg \& Sellier

\section{Édition imprimée}

Date de publication : 1 octobre 2008

Pagination : 488

ISSN : 0039-2944

\section{Référence électronique}

Geneviève Henrot Sostero, "Philippe Willemart, Critique génétique: pratiques et théories ", Studi Francesi [En ligne], 155 (LII | II) | 2008, mis en ligne le 30 novembre 2015, consulté le 12 janvier 2021. URL : http://journals.openedition.org/studifrancesi/9023; DOI : https://doi.org/10.4000/studifrancesi.9023

Ce document a été généré automatiquement le 12 janvier 2021.

\section{(c) (i) (9)}

Studi Francesi è distribuita con Licenza Creative Commons Attribuzione - Non commerciale - Non opere derivate 4.0 Internazionale. 


\title{
Philippe Willemart, Critique génétique: pratiques et théories
}

\author{
Geneviève Henrot Sostero
}

\section{RÉFÉRENCE}

PHILIPPE WILLEMART, Critique génétique: pratiques et théories, Paris, L'Harmattan, 2007

(«L'Euvre et la psyché»), pp. 278.

1 Spécialiste bien connu de la génétique proustienne et flaubertienne, fondateur et directeur du Laboratoire du Manuscrit littéraire de l'Université de São Paulo do Brasil, l'A. propose ici en édition française une constellation d'articles consacrés à la critique génétique. Cette publication chez L'Harmattan semble en effet avoir pour vœu de mettre à la disposition des lecteurs français (et européens) des textes brésiliens légèrement plus anciens, et d'accès improbable pour les chercheurs de l'Hexagone: les seize textes rassemblés furent publiés entre 1993 et 2005 dans des revues ou actes de colloques diffusés Outre-Atlantique. L'A. tisse ainsi de son gré une sorte de pont atlantique afin que ses publications brésiliennes puissent mieux atteindre leur havre de départ: L'Institut des Textes et des Manuscrits Modernes de l'Ecole Normale Supérieure de Paris, et en particulier son Equipe Proust, auquel l'A. appartient depuis de nombreuses années.

2 L'ouvrage s'articule en deux sections, annoncées par le titre. La première section («Pratiques de la critique génétique») ordonne autour de quatre corpus (Flaubert - ch. 1, 2, 3 -, Proust - ch. 4, 5, 6 -, Freud - ch. 7, 8 -, la ville de São Paulo, ch. 9) des enquêtes sur les divers mobiles et processus de la création, que celle-ci soit littéraire, scientifique ou urbanistique. Chacun apporte ses preuves aux échanges mutuels qui se tissent entre les codes (texte/image), la forme et les thèmes, les voies de la pensée (rêve/imaginaire/ souvenir), la fiction et la réalité clinique.

3 La seconde section («Théorisation de la critique génétique»), après une utile confrontation entre critique génétique et histoire littéraire (ch. 1), se penche tour à 
tour sur les relations entre l'inachevé et le temps dans les manuscrits (ch. 2), le jeu des passions entre savoir et ignorance (ch. 3), le rôle de la rature comme symptôme visible de la pensée dans l'écriture (ch. 4), la spécificité native de l'écriture littéraire (ch. 5 et 7). La lecture génétique de Freud et l'interprétation de la ville comme un manuscrit témoignaient déjà, dans la première section, d'une évidente élasticité de la pensée génétique, toujours plus encline à embrasser les corpus les plus divers (ce dont témoignent magistralement, entre autres, les numéros 8, 14, 20, 22 de la revue "Génésis», principal organe des nombreuses équipes génétiques de l'ITEM). L'A., partisan par ailleurs d'une rencontre fécondante entre disciplines, lecteur de PetitotCorcorda comme de René Thom ou d'Ilya Prigogine, s'attache ici à sonder les processus de la création dans les sciences dures (ch. 7).

4 Une Bibliographie, un Index des noms et un Index des concepts clôturent le livre. 